Original Article

\title{
DEVELOPMENT AND VALIDATION OF UV-SPECTROSCOPIC METHOD FOR ESTIMATION OF IPRATROPIUM BROMIDE IN API AND IN PHARMACEUTICAL DOSAGE FORM
}

\author{
BHAGYASHRI S. SHINDE ${ }^{1}{ }^{*}$, M. S. KALSHETTI ${ }^{1}$, ANJALI P. KOKANE1
}

Department of Quality Assurance, D. S. T. S Mandal's College of Pharmacy, Solapur, Maharashtra, India Email: ssshinde13579@gmail.com

Received: 13 Jun 2020, Revised and Accepted: 16 Aug 2020

\section{ABSTRACT}

Objective: To developed and validated UV spectrophotometric method for the estimation of ipratropium bromide in API and pharmaceutical formulation.

Methods: Methanol is used as a solvent and the absorbance of the drug was measured at absorbance's maxima of ipratropium bromide max is 214 nm.

Results: Maximum absorbance obtained in $214 \mathrm{~nm}$. Calibration curve plotted in concentration range 20-120 $\mu \mathrm{m} / \mathrm{ml}$ exhibit the linearity relationship with line equation $y=.0 .0091 x+0.1503$ The Accuracy was found to be $99.7-100.2 \%$, the precision $\% \mathrm{RSD}=0.08613-0.2668$, and the LOD and LOQ is $6.33,19.19$. The method was found to comply all the validation parameters as per the ICH guideline indicating the sensitivity of the method analyte.

Conclusion: This method is used as satisfactory for the routine analysis of ipratropium bromide in API and pharmaceutical dosage forms.

Keywords: Ipratropium bromide, UV Spectrophotometer, Methanol, Validation

(C) 2020 The Authors. Published by Innovare Academic Sciences Pvt Ltd. This is an open access article under the CC BY license (http://creativecommons.org/licenses/by/4.0/) DOI: http://dx.doi.org/10.22159/ijcpr.2020v12i5.39760. Journal homepage: https://innovareacademics.in/journals/index.php/ijcpr

\section{INTRODUCTION}

Ipratropium Bromide chemically is [8-methyl-8-(1-methyl ethyl)-8azoniabicyclo [3.2.1] oct-3-yl] 3-hydroxyl-2-phenyl-propanoate (fig. 1). Ipratropium bromide was used for various bronchial disorders in rhinitis and as an antiarrhythmic [1,2]. It is opens up the medium and large airways in the lungs. Ipratropium bromide is stable and it affects the safety and efficacy of the finished drug product. Ipratropium bromide is freely soluble in water, methanol and sparingly soluble in ethanol. In this method, methanol is used as a solvent. Various methods were developed by using HPLC, IR, MS, UV and others $[3,4]$.

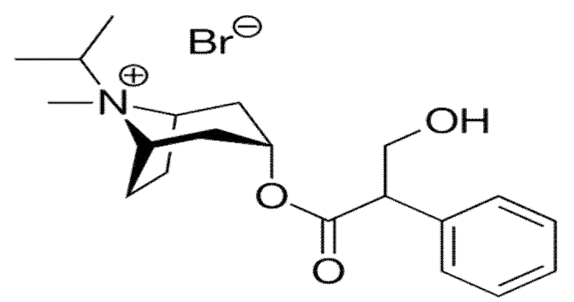

Fig. 1: Chemical structure of ipratropium bromide [5]

\section{MATERIALS AND METHODS}

\section{Selection of solvent and instruments}

Ipratropium bromide is dissolving in various solvents for trails of selecting the ideal solvent. Various solvents i.e. water, methanol, ethanol, acetonitrile. Ipratropium bromide is soluble in methanol and better absorption was found to be at $214 \mathrm{~nm}$. UV-Visible Spectrophotometer (shimadzu AY220) is used for this study.
API-Ipratropium Bromide was obtained as a gift sample from the vamsi Pharmaceutical Ltd. Solapur, Maharashtra. Capsule of $40 \mathrm{mg}$ is purchased from the local pharmacy in Solapur. Brand name is Ipravent (Cipla) methanol was used for this study.

Experimental work

Method development

Selection of detection wavelength

Dilution of Ipratropium bromide was prepared from the stock solution $(50 \mu \mathrm{g})$. Ipratropium bromide was scanned over a range of 200-400 nm. Drug showed maximum absorbance at $214 \mathrm{~nm}$ was selected as the wavelength for detection.

Preparation of standard drug solution

$10 \mathrm{mg}$ of Ipratropium bromide was weighed and transferred into a $10 \mathrm{ml}$ volumetric flask containing methanol. Concentration of stock solution is $(1000 \mu \mathrm{g} / \mathrm{ml})$. Then pipette out $2 \mathrm{ml}$ form the stock solution and adjust to volume.

\section{RESULTS AND DISCUSSION}

Method validation [6]

The method was validated for several parameters i.e. Accuracy, Linearity, Precision, Robustness, Ruggedness, Limit of Detection, Limit of Quantification [6].

\section{Accuracy}

Accuracy is defined as, analytical procedure it expresses the closeness of an agreement between the value that is accepted and either as a true conventional value. This study was carried out at three different levels that are $80 \%, 100 \%, 120 \%$, by the standard addition method. Analyzed samples by triplicate by according to the method. Known amount of standard ipratropium bromide was a spike on the capsule sample. Check the absorbance and calculated (table 1)

$\%$ Recovery= observed value/true value $\times 100$ 


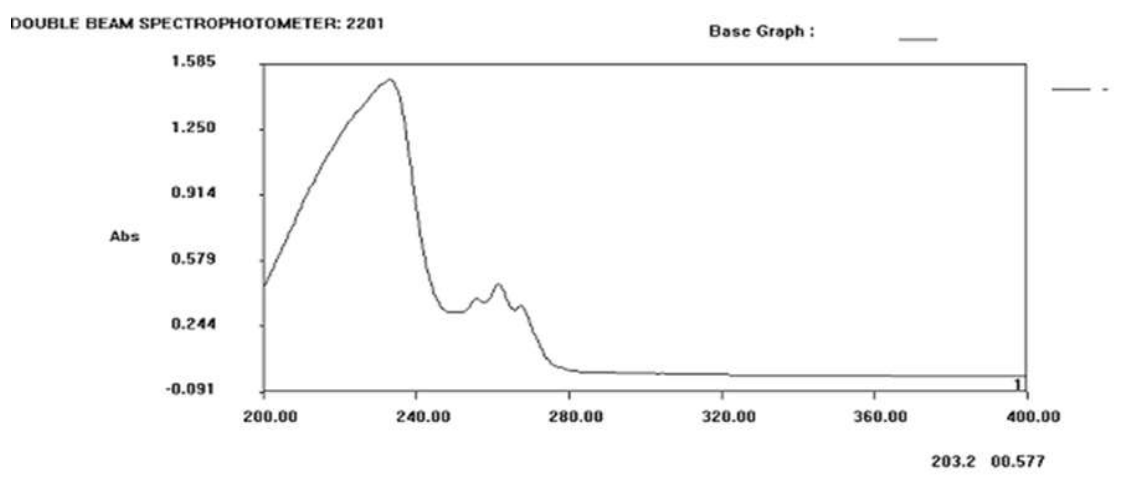

Fig. 2: UV visible spectrophotometer graph

Table 1: Result of accuracy

\begin{tabular}{|c|c|c|c|c|c|c|}
\hline S. No. & \% level & Spike amount $(\mu \mathrm{g} / \mathrm{ml})$ & $\begin{array}{l}\text { Spiked amount (wrt } \\
\text { sample) }\end{array}$ & Abs. & $\begin{array}{l}\text { Amount } \\
\text { recovered }\end{array}$ & $\begin{array}{l}\% \text { RSD } \\
\% \text { recovery }\end{array}$ \\
\hline 1 & 80 & 79.911 & 79.9 & 0.861 & 101.7 & 0.7 \\
\hline 2 & 100 & 99.889 & 99.9 & 1.038 & 99.7 & 0.9 \\
\hline 3 & 120 & 119.867 & 119.9 & 1.253 & 100.2 & 1.1 \\
\hline
\end{tabular}

Based on the \% recovery data, it was concluded that the developed method is used for the estimation of ipratropium bromide and is adequate for routine analysis.

\section{Linearity and range}

Linearity is defined as an ability of the analytical procedure to obtain test results, which is directly proportional to the concentration of the analyte in the sample. Pipette out $1,2,3,4,5,6 \mathrm{ml}$ of standard ipratropium bromide solution in a $10 \mathrm{ml}$ calibrated volumetric flask. Adjust the volume up to the mark with methanol. Concentration of this solution is $20,40,60,80,100,120 \mu \mathrm{g} / \mathrm{ml}$. Taking the absorbance at $214 \mathrm{~nm}$ and calculating the correlation coefficient. Range is $(20-$ $120 \mu \mathrm{g} / \mathrm{ml}$ ).

Table 2: Result of linearity

\begin{tabular}{lll}
\hline S. No. & Concentration $(\boldsymbol{\mu g} / \mathbf{m l})$ & Absorbance \\
\hline 1 & 20 & 0.352 \\
2 & 40 & 0.489 \\
3 & 60 & 0.698 \\
4 & 80 & 0.87 \\
5 & 100 & 1.05 \\
6 & 120 & 1.25 \\
\hline
\end{tabular}

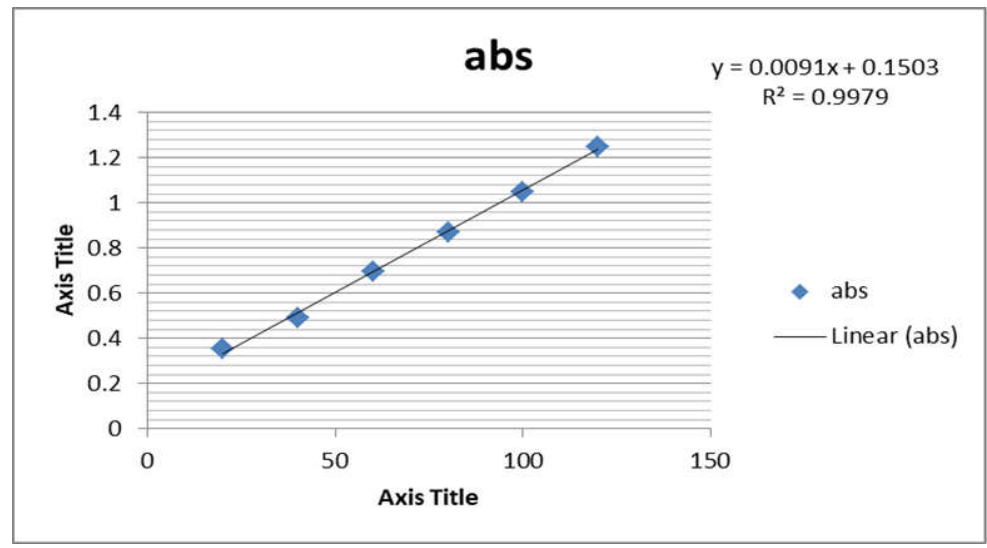

Fig. 3: Calibration curve of ipratropium bromide

By taking six different concentrations for linearity, the regression coefficient was found to be 0.997 i.e. in the limit of standard. Hence the linearity parameter was found to be validated (table 2, fig. 3).

\section{Precision}

Precision is defined as an analytical procedure is to define the closeness of agreement between a sample of measurements 
obtained from multiple sampling of the same homogenous sampling in specific conditions. It is determined by an inter-day, intra-day study. Reading is taking 3times on the same day. The percent relative standard deviation (\%RSD) was calculated. Precision results were given in the table 3 and 4 for intra and inter-day precision respectively.

Table 4: Result of Intra-day morning precision

\begin{tabular}{llll}
\hline S. No. & Concentration $(\boldsymbol{\mu g} / \mathbf{m l})$ & Absorbance & SD \\
\hline 1 & 80 & 0.874 & \\
2 & 80 & 0.875 & \\
3 & 80 & 0.873 & 0.000753 \\
4 & 80 & 0.874 & \\
5 & 80 & 0.875 & 0.08613 \\
6 & 80 & 0.874 & \\
\hline
\end{tabular}

Table 5: Result of inter-day precision

\begin{tabular}{llll}
\hline S. No. & Concentration $(\boldsymbol{\mu g} / \mathbf{m l})$ & Absorbance & \%SD \\
\hline 1 & 80 & 0.873 & \\
2 & 80 & 0.879 & \\
3 & 80 & 0.877 & 0.002338 \\
4 & 80 & 0.878 & 0.198804 \\
5 & 80 & 0.877 & \\
6 & 80 & 0.874 & \\
\hline
\end{tabular}

For Intra-day and inter-day precision relative standard deviation is in limit i.e. less than $2 \%$ hence parameter is validated (table 4,5$)$

\section{Limit of detection}

Detection limit is defined as the lowest amount of analyte in a sample can be detected. It is calculated based on the standard deviation of the absorbance of the same concentration that is a standard stock solution of $80 \mu \mathrm{g} / \mathrm{ml}$ of ipratropium bromide.

$\mathrm{LOD}=3.3(\mathrm{SD} / \mathrm{S}) \mathrm{SD}=$ Standard deviation, $\mathrm{S}=$ slope of the curve

Table 6: Result of limit of detection

$\mathrm{LOD}(\mu \mathrm{g} / \mathrm{ml}) \quad 6.33$

The LOD was found to be $6.33(\mu \mathrm{g} / \mathrm{ml})$. Hence the parameter was found to be validated (table 6).

\section{Limit of quantification}

Limit of quantification is defined as, it is based on the standard deviation of the peak area of the same concentration that is standard solution prepared and calculated by LOQ

$\mathrm{LOQ}=10(\mathrm{SD} / \mathrm{S}) \mathrm{SD}=$ Standard deviation, $\mathrm{S}=$ slope of the curve

\section{Robustness}

Robustness is defined as, the capacity of analytical procedure to remain unaffected by small changes or these method deliberate small variation in the method parameters. Main aim of this test is create a method that allows for some variations in the parameters. In this study wavelength was change at $\pm 5 \mathrm{~nm}$ that is $214 \mathrm{~nm}$ and $216 \mathrm{~nm}$. Then robustness is calculated (table 8)

\section{Ruggedness}

Ruggedness is defined as, reproducibility of the results when the defined method was performed under different analysts, laboratories, columns, chemicals, solvents, instruments, sources of reagents and etc.

Table 7: Result of limit of quantification

\begin{tabular}{lc}
$\mathrm{LOQ}(\mu \mathrm{g} / \mathrm{ml})$ & 19.19 \\
\hline
\end{tabular}

The LOQ was found to be19.19 ( $\mu \mathrm{g} / \mathrm{ml}$. Hence the parameter was found to be validated (table 7).

Table 8: Result of Robustness of ipratropium bromide

\begin{tabular}{|c|c|c|c|c|}
\hline S. No. & Wavelength & Absorbance & SD & \%RSD \\
\hline \multirow[t]{4}{*}{1} & 214 & 0.874 & & \\
\hline & & 0.876 & 0.001528 & 0.174 \\
\hline & & 0.873 & & \\
\hline & & $A v g=0.874$ & & \\
\hline \multirow[t]{4}{*}{2} & 216 & 0.872 & & \\
\hline & & 0.873 & 0.001528 & 0.174 \\
\hline & & 0.875 & & \\
\hline & & $A v g=0.873$ & & \\
\hline
\end{tabular}

The change in the wavelength i.e. $216 \mathrm{~nm}$. The robustness was found to be within limit i.e. relative standard deviation is less than $2 \%$. Hence the parameter was found to be validated (table 8) 
Table 9: Result of the ruggedness of ipratropium bromide

Analyst 1

\begin{tabular}{lll}
\hline Concentration & Absorbance & Statistical analysis \\
\hline 80 & 0.874 & Avg $=0.874$ \\
80 & 0.875 & SD $=0.0015$ \\
80 & 0.873 & $\%$ RSD $=0.114$ \\
\hline
\end{tabular}

Table 10: Result of ruggedness of ipratropium bromide

Analyst 2

\begin{tabular}{lll}
\hline Concentration & Absorbance & Statistical analysis \\
\hline 80 & 0.877 & Avg $=0.875$ \\
80 & 0.875 & SD $=0.0015$ \\
80 & 0.874 & $\%$ RSD $=0.114$ \\
\hline
\end{tabular}

Ruggedness was calculated by taking analyte at two different analyte and the respective absorbance was noted and obtained results shown that does not affected by it (table 9,10 )

\section{CONCLUSION}

UV spectrophotometric method of ipratropium was developing method is simple, precise, rapid, and accurate. Method is developing and validated by pure API and its capsule formulation. These method used for the routine determination of ipratropium bromide in bulk and pharmaceutical dosage formulation

\section{ACKNOWLEDGEMENT}

Authors are thankful to the D. S. T. S. Mandal's College of Pharmacy, Solapur, Maharashtra India for providing the facility for conduct of the research work. Authors are also thankful to Prof. Dr. M. S. Kalshetti for their consistent support and assistance throughout the research work.

\section{FUNDING}

Nil

\section{AUTHORS CONTRIBUTIONS}

All the authors have contributed equally.

\section{CONFLICT OF INTERESTS}

Declared none

\section{REFERENCES}

1. Anjali Kokane, Varsha Tegeli, Bhagyashri Shinde. UVspectrophotometric method development and validation for estimation of ipratropium bromide in API and pharmaceutical dosage form. Int J Curr Pharm Res 2020;12:69-73.

2. https://www.Drugbanh.ca/drugs/DB00332 [Last accessed on 10 May 2020]

3. P Nagarju, SCHVSS Appaji. Development and validation of novel RP-HPLC method for simultaneous estimation of levosalbutamol and Ipratropium bromide in pharmaceutical dosage form. Int J Res Pharm Chem 2014;4:635.

4. Gummadi Sowjanya, D Gowri Sankar, JVLN Seshagiri Rao. Development and validation of a new RP-HPLC method for the simultaneous determination of of albuterol sulphate and Ipratropium Bromide in nasal inhalation. Int Res J Pharm Step 2018;9:63-70

5. K Kranthi Kiran. A new analytical method development and validation for the simultaneous estimation of albuterol and Ipratropium bromide using RP-HPLC. Int J Pharma Investigation Res 2017;4:72-95.

6. ICH, Q2 (R1) Validation of analytical procedures: text methodology, international conference on harmonization; 1196.

7. Ravi Vankudoth, RP Pulla, B Umasankar, G Saisneha, S Chawan, A Aparna. RP-HPLC method for simultaneous estimation of Ipratropium bromide and levolbutamol in pharmaceutical metered-dose inhalers. IJRPC 2013;3:2231-781.

8. GB Kasawar, M Faooqui. Development and validation of stability indicating RP-HPLC for the simultaneous determination of related substance of Albuterol sulphate and Ipratropium bromide in nasal solution. J Pharm Biomed Anal 2010;52:19-20.

9. A Rasheed, 0 Ahmed. Analytical separation and characterization of degradation product and the development and validation of stability indicating method for the estimation of impurities in Ipratropium bromide respules formulation. Int J Appl Pharm Sci Res 2017;2:55-63.

10. SM Raj, VJ Jamakandi. Estimation of Ipratropium bromide by extraction free spectrophotometric method using sulphonapthalein dye. Int J Pharm Sci Res 2017;24:4605-12.

11. Chester C. Wood, Philip Fireman, Jay Grossman, product characteristics and pharmacokinetics of intranasal ipratropium bromide. J Allergy Clin Immunol 1995;95:1111-6. 